\title{
OUTLOOKS ]
}

"We are further exploring the impact of the remotely sensed observations, and attempting to determine which of the observations are having the greatest impact. NOAA is still working to evaluate and increase the number of UAS observations (particularly from smaller platforms) to help conduct our mission."

- Gary Wick, NOAA

PAGE 775

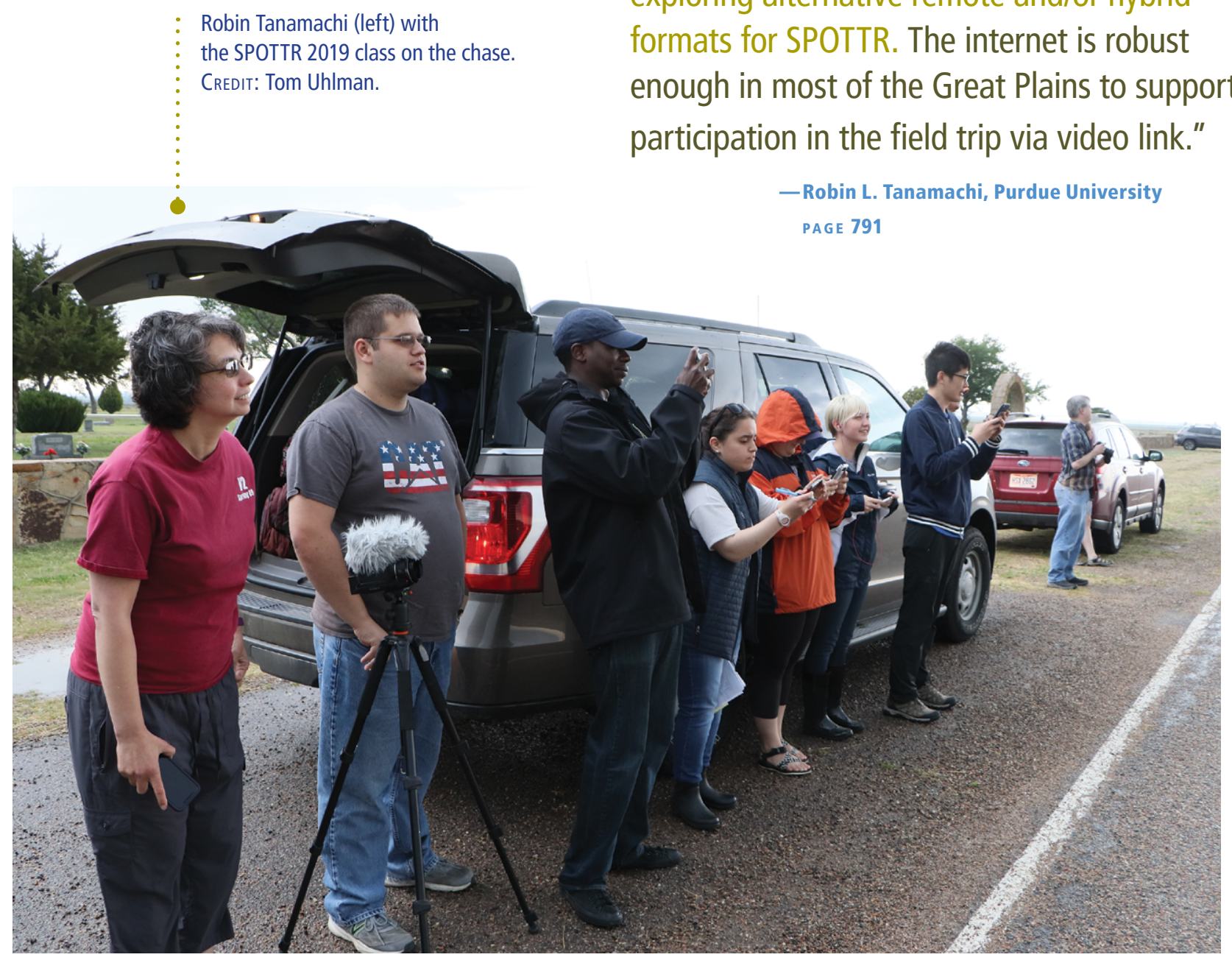

"In 2020, our storm chasing course, SPOTTR, was, unfortunately, canceled due to COVIDrelated travel restrictions. I am interested in exploring alternative remote and/or hybrid formats for SPOTTR. The internet is robust enough in most of the Great Plains to support participation in the field trip via video link."

— Robin L. Tanamachi, Purdue University PAGE 791 


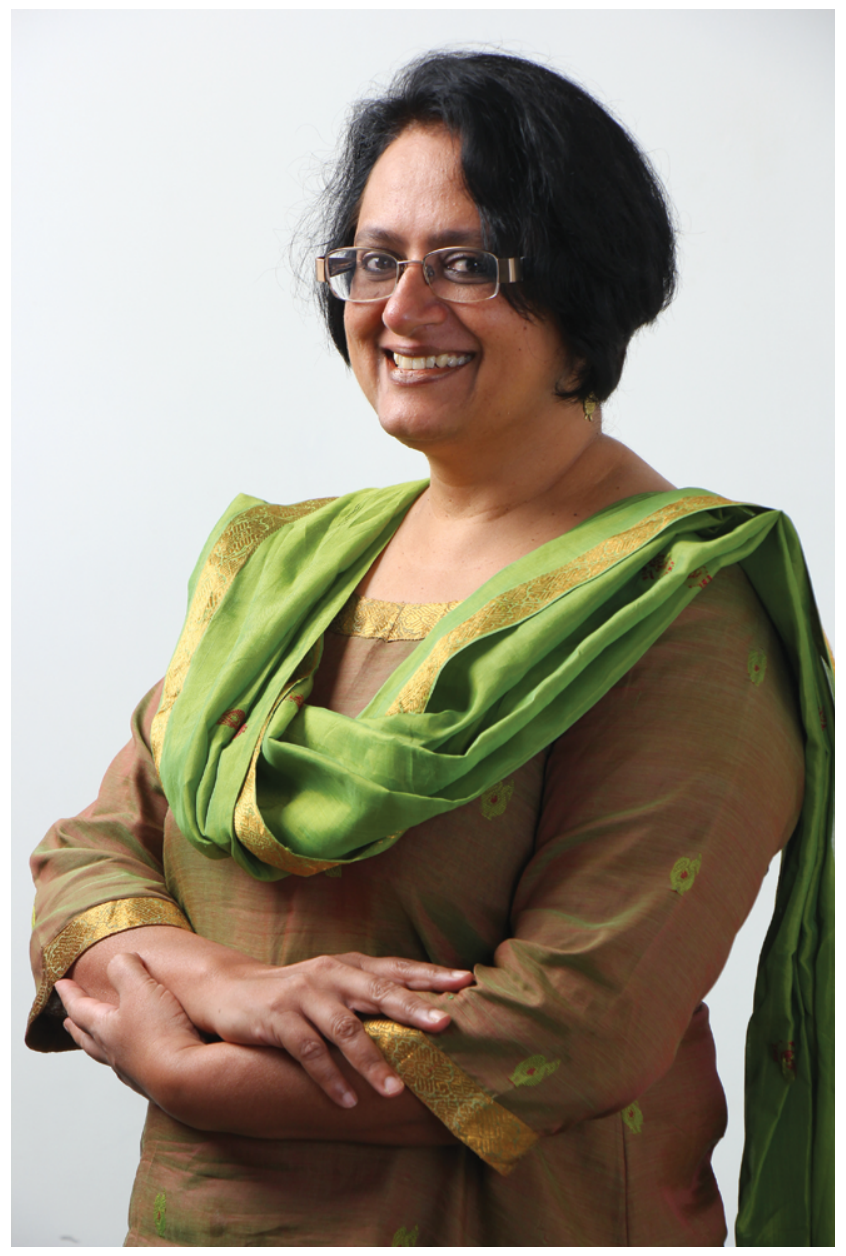

"Typically, industry, electricity generation, and transportation are targets of air pollution control and climate mitigation. The COALESCE project aims to bring nonformal sectors like residential, agriculture, and brick production under the joint purview of clean air and climate action. We hope that the tools and datasets we've developed will be widely exploited in pursuit of India's action plans related to improving air quality and to meeting climate change commitments."

\section{-C. Venkataraman, Indian Institute of Technology PAGE 779}

"The climate prediction research community will continue to work toward understanding the predictability of the Earth system better, improving prediction models and methodologies, and translating these developments into services. I expect that in several years the community will convene again to share an entirely new set of exciting developments."

\footnotetext{
—William Merryfield, Environment and Climate Change Canada PAGE 767
}

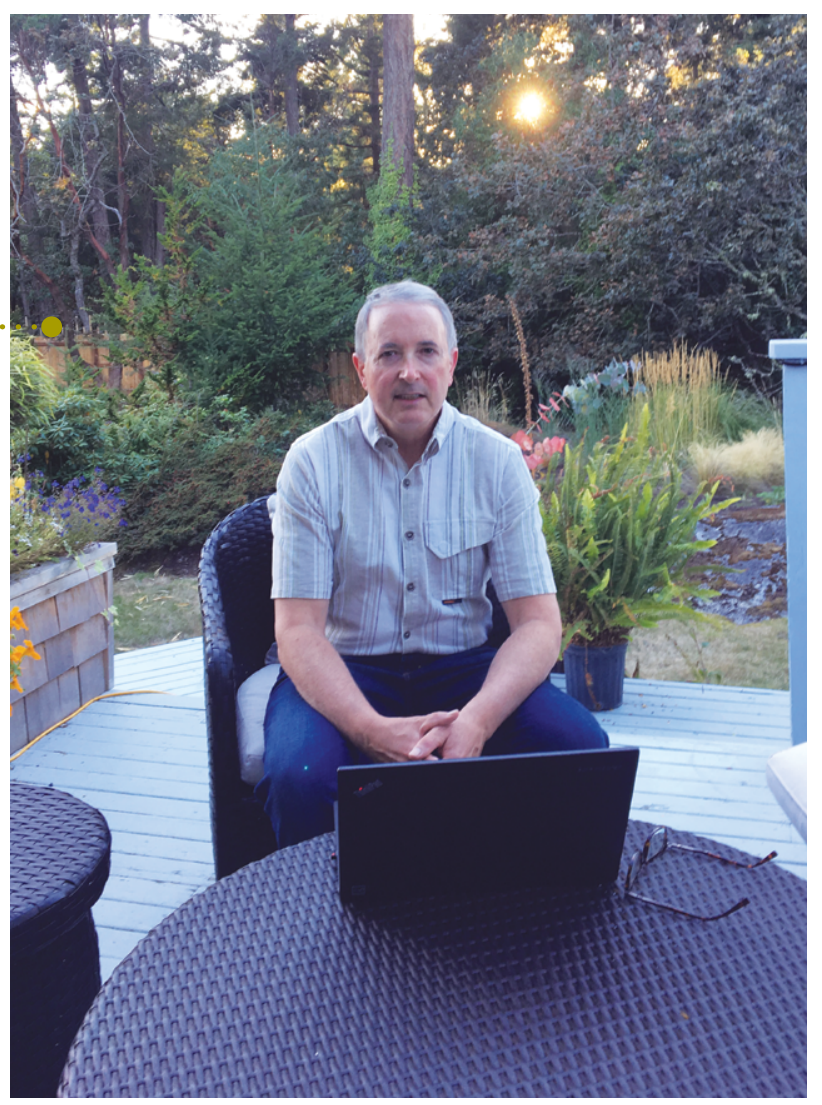


OUTLOOKS ]

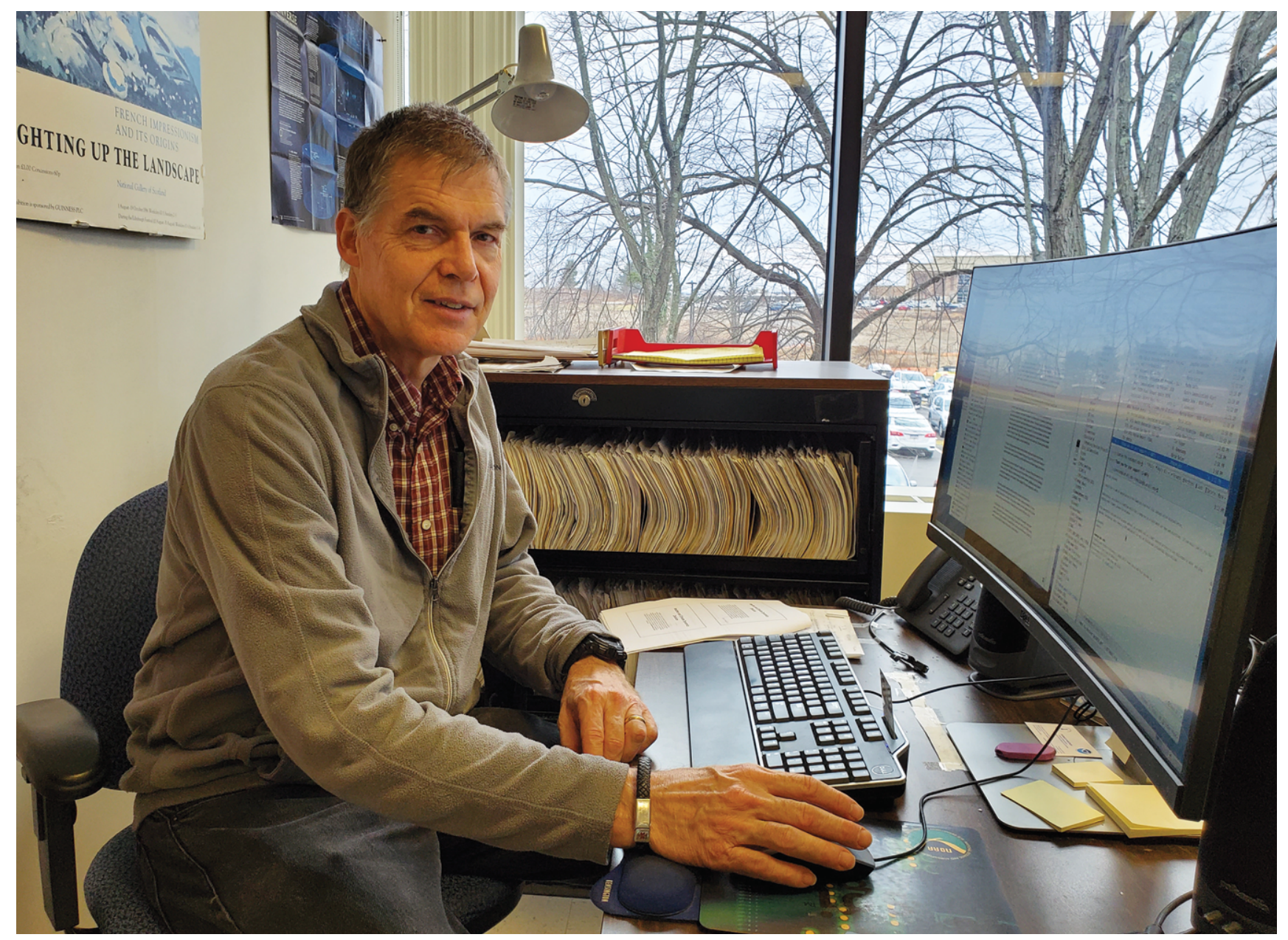

"Future revisions will be made to our assessment conclusions based on new data (as more future years of hurricane data become available), improved models, improved understanding, and new studies. This is not the final word. That's how science operates."

\section{-Thomas Knutson, NOAA/GFDL}

PAGE 771 